\title{
"Eu não sei o que é o Moçambique profundo ou verdadeiro" Entrevista a Mia Couto
}

\author{
DORIS WIESER \\ Universidade de Lisboa - Lisboa - Portugal \\ 27
}

Maputo, 18 de Julho de 2014: É inverno. Os moçambicanos queixam-se do frio, que por vezes desce aos treze graus durante a noite. Porém, de dia a temperatura é muito agradável, pelo menos para quem vem da Alemanha fazer investigação, como é o meu caso. ${ }^{1} \mathrm{O}$ sol brilha, mas não é demasiado intenso, nem para o trabalho académico, nem para o passeio que estou a ponto de empreender. Às nove da manhã inicio o meu caminho a pé do bairro Malhangalene até ao famoso bairro da Polana, de classe alta, limpo e ordenado, que conta com um dos hotéis mais exclusivos da África e que quase me faz esquecer que estou num dos países mais pobres do mundo, se não fosse pela maneira descuidada de conduzir dos automobilistas e pelas (embora escassas) mulheres vestidas com capulanas.

Hoje é o dia do meu encontro com o escritor-biólogo Mia Couto (*1955, Beira), personagem que não precisa ser apresentado desde que foi galardoado com o Prémio Camões em 2013. Às 10 horas entro no edifício da Impacto na Av. Mártires da Machava, a empresa do escritor que se dedica a fazer estudos e projetos ambientais. ${ }^{2}$ Há muito movimento, pessoas a entrar e a sair, telefones a tocar. Pedem-me para aguardar uns minutos, mas Mia Couto aparece logo, cumprimenta-me com o seu ar sempre amigável e comedido. Guia-me ao seu gabinete, no fundo, não sem antes me oferecer um café. Neste ambiente tranquilo, resguardado do alvoroço da rua e da agitação da empresa, falámos uma hora sobre diversos aspetos da cultura e da sociedade moçambicanas e, naturalmente, sobre a literatura.

1 Nas suas obras sempre há personagens de diferentes origens e cores da pele: indianos, portugueses, mulatos, africanos negros... Como mudou a imagem estereotípica dos portugueses da época colonial até hoje?

Eu acho que não existe obviamente uma coisa chamada moçambicanos ou Moçambique. Há várias visões, há várias apreciações. É muito difícil analisá-las. No ambiente urbano, que eu conheço melhor, a apreciação sobre os portugueses é uma apreciação ambivalente. No geral, eu acho que continua a ser uma apreciação colonizada porque se dá demasiada importância. Eu acho que a apreciação fica descolonizada quando os portugueses têm a mesma importância de qualquer outro. É um caso em particular por razões históricas, por algum

\footnotetext{
1 Agradeço à Fundação Fritz Thyssen (www.fritz-thyssen-stiftung.de) pelo financiamento desta viagem de investigação a Moçambique do 5 de julho ao 5 de agosto de 2014.

2 Página da empresa: <www.impacto.co.mz/01_Home_Page.html $>$.
}

ressentimento que ficou. Mas, em geral, não há uma atitude negativa ou particularmente agressiva em relação aos portugueses.

A situação melhorou muito e depois voltou a piorar, porque começou a aparecer em Moçambique uma nova vaga de portugueses que nem sempre tinha uma atitude muito simpática, de convívio positivo. Então, acho que, no geral, os portugueses são vistos como "os outros". Só que aqui é preciso dizer que essa grande fronteira, entre "nós" e "os outros", aqui nem sempre se faz entre "nós, os moçambicanos" ou mesmo "nós, os negros" e "os outros". As fronteiras são muito voláteis e fluídas.

Vou muitas vezes a um trabalho de campo, e eu sou o único branco, todos os meus colegas são negros. Chegamos a uma aldeia e as pessoas dizem: "São valungo, chegaram os brancos". Branco - "valungo" no plural, "mulungo" no singular - não quer dizer propriamente a cor da pele. Uma pessoa pode ser um mulungo, desde que se comporte como um branco, desde que se comporte como "os outros", 
não fala a mesma língua, não tem a mesma cultura. Esses são "os outros", os que não são próprios do lugar. Isso aqui no Sul, por exemplo, é muito notório, porque o Sul teve historicamente pequenas regiões autónomas. Não havia um Estado unificado, só depois com o império de Gaza, em meados do século XIX, aqui houve um Estado central. ${ }^{3}$ Os chonas, na parte central de Moçambique, têm um Estado muito mais antigo, monolítico, centralizado, de administração única. Então, essa existência histórica de um Estado unifica apreciações e até a própria religião. No centro, no império chona, que vem do mesmo tempo antigo do Monomotapa, ${ }^{4}$ a ideia de um deus criador está completamente presente. Aqui no Sul os deuses, no plural, são dispersos.

Este assunto não é simples. Tem critérios religiosos, critérios sociais, critérios de cultura, da língua que se fala. Se a Doris for a um sítio de Moçambique e souber falar a língua do lugar deixou de ser branca, deixou de ser "mulunga". Passou a ser própria. Então, a fronteira não é a fronteira apenas da cor da pele, mas de muitas outras coisas.

2 Na época colonial, havia uma classe intermédia, os assimilados. Esta categoria ainda tem algum peso?

$\square$ Eu acho que não, mudou muito, mas o que aconteceu foi que estes movimentos nacionalistas foram criados muito à volta de um certo tipo de assimilados que também não era o único. Não havia só um padrão de assimilados. Havia assimilados por via de administração do Estado português, mas também na conquista das missões católicas e protestantes.

Eu acho que o Estado moçambicano pós-independência foi construído na base de uma lógica europeia. Os assimilados realmente estavam preparados para fazer a gestão do Estado. E é muito curioso, o projeto português era que os assimilados fossem leais à dominação colonial. Mas foram exatamente estes que depois foram mais ativos em criar um movimento de contestação e de independência.

3 Usa muitas vezes a perspetiva de uma personagem urbana, um "mulungo", um estrangeiro ou um branco para representar o mundo rural africano (pensemos em $A$ Varanda do Frangipani, A Confissão

\footnotetext{
O Império de Gaza sucumbiu aos portugueses em 1895. O seu declínio é tema de um romance clássico da literatura moçambicana contemporânea: Ualalapi, de Ungulani Ba Ka Khosa (1987).

4 O Império Monomotapa remonta ao século XV e dissolveu-se no século XVIII. A sua capital foi o Grande Zimbabwe cujas ruinas fazem parte do Património Mundial da UNESCO desde 1986.

5 As três são etnias do Norte do país, radicadas nas províncias Zambézia, Nampula (macuas), Niassa (ajauas) e Cabo Delgado (macondes e macuas).
}

da Leoa, Venenos de Deus e Remédios do Diabo e também em Jesusalém...). É um método para traduzir a cultura africana para um público europeu?

Não. Eu faço, porque eu próprio sou essa pessoa que estou chegando também. Porque eu, mesmo sendo de Moçambique, também sou um moçambicano particular da origem portuguesa. Sou de uma cidade, sou urbano. E esse universo que é o universo a que eu quero abrir as portas é o universo rural. Quando chego lá, eu sou essas personagens também. É como se eu estivesse a decifrar eu próprio. Eu sinto que não estou a falar de um território concreto. $\mathrm{O}$ território que eu quero revelar é o território sobretudo da linguagem, é o território do domínio da literatura. Eu não sou um anfitrião ou um guia turístico para mostrar: "Olha, é aqui o verdadeiro Moçambique." Eu não sei o que é o Moçambique profundo ou verdadeiro. O que eu quero mostrar é que há uma travessia que os próprios moçambicanos também têm de fazer. Não só eu, como moçambicano de origem estrangeira, tenho esse problema. Qualquer outro moçambicano com raízes moçambicanas tem de fazer essa viagem, essa travessia. Se ele for macua, ele não conhece os macondes, não conhece os ajauas. ${ }^{5}$ Então, esta diversidade estrutural que Moçambique tem, com povos que se desconhecem, línguas, religiões e culturas diferentes, implica sempre essa viagem dentro dos Moçambiques vários.

4 Moçambique é um espaço político criado através da colonização que desrespeitou as fronteiras culturais. Este espaço político chegou a criar, através do tempo, também um espaço cultural e identitário? Há hoje em dia um sentimento de pertença a um espaço cultural comum?

Acho que sim. Acho que mesmo antes da independência começou uma história por via das guerras que eram feitas da história, da relação que era criada com certo tipo de poder, com certo tipo de cultura porque os europeus tiveram métodos diferentes, tiveram culturas diferentes. Uma coisa foi a colonização portuguesa e outra a colonização inglesa aqui ao lado. Isso criou um sentido deste lado e do outro lado. Curiosamente, essa construção começou pela negação. Nós não queremos ser portugueses, não queremos pertencer a Portugal. Então, nessa oposição, não só se criou uma política, mas também uma cultura própria. A FRELIMO criou uma cultura própria.

5 Fala-se muito de que o Sul de Moçambique é marcado por estruturas patriarcais e o Norte por matriarcais. A Confissão da Leoa desenrola-se no Norte, mas neste romance as mulheres parecem sofrer de igual maneira a violência doméstica. Em 
que medida as culturas matriarcais continuam vivas hoje em dia?

$\square$ Acho que essa ideia das culturas matriarcais e patriarcais é uma invenção dos antropólogos. No Norte, onde se diz que existe essa cultura matriarcal, acho que existe um poder patriarcal absoluto. Digamos que no Norte ainda prevalece alguma coisa que é uma capa, uns elementos simbólicos, que ainda estão lá as mulheres sendo rainhas. Mas a mulher sendo rainha, quem manda continua a ser o tio paterno, os conselhos dos anciões que são dominados por homens. Eu não concordo com a ideia simplista de fazer esta fronteira "Norte matriarcal" e "Sul patriarcal". De uma maneira subterrânea, Moçambique é todo ele uma sociedade altamente patriarcal com um poder absoluto nos homens.

\section{Como é visto o espaço urbano pela população} do interior e vice-versa? São dois mundos diferentes ou dialogam?

Acho que agora é que está a começar o fenómeno da urbanização mais radical, em que quem vem para a cidade perde aquilo que era a sua raiz no campo, e tem de se transformar noutra criatura. Até muito recentemente, quem vinha para Maputo mantinha uma parte de sua família no campo e fazia trocas permanentes. Aquilo que ele recebia como salário na cidade era apenas uma pequena parte do seu rendimento, porque ele buscava o resto da mulher ou das mulheres que ele tinha. Era como se a cidade fosse um outro país de emigração. Aliás, a cidade, até há muito pouco tempo, era chamada na rua como "Xilunguine". Xilunguine é o lugar onde se fala "xilungo", a língua dos brancos, o português. Portanto, em Maputo, só agora está a parecer um território urbano realmente, de cultura urbana. A maior parte dos moradores da cidade são de primeira ou de segunda geração, não mais que isso. Então, a fronteira entre o urbano e o rural ainda é muito esbatida. As pessoas não são completamente urbanas no sentido da sua cultura, de seu modo de ser. Muita gente nem circula no passeio, circula na estrada, porque a definição do espaço público é a mesma que tinha quando estava no seu lugar rural.

7 Na sua obra os nomes dos lugares são muito importantes: Vila Cacimba (em Venenos de Deus, Remédios do Diabo), Jesusalém (em Jesusalém), a Ilha do Luar-do-Chão (em Um Rio Chamado Tempo, uma Casa Chamada Terra). Também os nomes das personagens: Tio Abstinêncio, Tio Aproximado, Bartolomeu Sozinho... Em que medida isto é um recurso poético e em que medida traduz uma visão do mundo africano?

É uma mistura. A minha intenção era mostrar que esses nomes logo à partida mostram que eu estou ficcionando. Eu não estou a fazer de conta que estou a falar da realidade. Não quero que haja uma leitura naturalista do assunto. E, portanto, é como uma espécie de lealdade ao leitor: Eu estou a mentir, mas eu estou a dizer que é mentira. Por outro lado, os moçambicanos não têm só um nome. Há regiões em Moçambique em que a pessoa tem vários nomes ao longo da sua vida. E, se abrir a página dos anúncios funerários, normalmente tem um nome, depois entre parênteses tem o outro nome. Portanto, a relação com os nomes não é a mesma coisa que na Europa, onde a pessoa tem um nome e esse nome é a sua identidade. Aqui as pessoas podem ter um, dois, três nomes diferentes.

\section{Mas eles só têm um nome no documento oficial.}

$\square \quad$ No documento oficial só tem um nome. Mas depois em casa tem outro nome, no campo tem outro. Porque as pessoas vivem em mundos diferentes, no mundo oficial, no mundo formal onde a pessoa tem de habitar e tem de ter esse nome, normalmente um nome português. Mas depois tem o espaço de família, mais íntimo, onde tem outro nome, e pode acontecer que o nome da infância e da adolescência ainda seja outro.

9 Tenho observado que existe uma certa tensão entre a tradição africana e a "modernidade" europeia. Que elementos das culturas portuguesa ou europeia e que elementos das culturas africanas se valorizam particularmente em Moçambique? E como convivem?

Existem tensões. Eu acho que os moçambicanos têm uma grande apetência pela modernidade. Querem estar no mundo moderno. O que é bom, antes isso do que quererem ficar fechados na chamada "tradição". Mas existe também a ideia que as tradições mais antigas podem perder-se. Existe este risco. É preciso entender uma coisa que é invisível, o lado religioso. Eu sugiro que procure esse lado como lado fundamental. Eu não posso entender a Europa se não entendo a história das religiões na Europa, o catolicismo, o protestantismo, o que é ser protestante na Europa, o que é ser católico. Se eu não entendo isso, é difícil entender a história da Europa.

Em Moçambique há uma religiosidade, nem é bem uma religião, que às vezes é chamada de animista. A relação com os antepassados é fundamental. Quase todos os moçambicanos, 90 por cento dos moçambicanos têm essa religião. Depois, são católicos ou protestantes mas ao mesmo tempo. Eles têm essa habilidade de fazer essa permuta, essa fusão, têm habilidade de fazer o resto porque a religião é o mais íntimo, o chão da alma das pessoas. Acho que vale a pena perceber isso. Senão, fica difícil, porque um dia Moçambique parece uma coisa, outro dia Moçambique já parece outra coisa, porque não se percebeu o que é que estava por baixo. 
10 Qual o papel do administrador legal e do chefe tradicional nas vilas e aldeias hoje em dia? Às vezes é a mesma pessoa ou são duas pessoas diferentes? Não é. Há dois.

\section{O chefe tradicional tem algum documento oficial para sustentar sua posição?}

No princípio, quando foi a revolução em Moçambique, desde a Independência até 1985/1986, a tradição era mal vista. Era aquela atitude primeiro marxista... Queria-se fazer um país completamente moderno, de acordo com o modelo da União Soviética, fosse o que isso fosse. Portanto, o chefe tradicional era visto como uma coisa obscurantista a ser eliminada. E foram perseguidos e não se aceitavam. Num segundo momento, por causa do próprio conflito com a RENAMO, percebeu-se que isso não era possível fazer e era politicamente muito perigoso. Sobretudo, estava-se a criar uma mentira, uma situação ilusória. Então, fez-se uma certa recuperação desse mundo tradicional, das autoridades tradicionais. Mas nunca foi muito claro que atribuições tem realmente um chefe tradicional, o régulo. Eles continuam a ser uma coisa mais ou menos folclórica. Em certas ocasiões são chamados, mas ainda falta fazer a definição: o que é que faz exatamente o régulo e o que é que faz o chefe formal, o representante do Estado moderno.

\section{O chefe tradicional é uma pessoa diferente do curandeiro? Ou pode ser a mesma pessoa?}

Pode ser a mesma pessoa, mas em geral são duas pessoas diferentes. O próprio termo curandeiro também tem de ser sempre esclarecido, porque existem categorias diferentes: curandeiro, feiticeiro, adivinhador, que aqui no Sul tem certos nomes, como o sangoma, por exemplo, que usa tambores para fazer uma certa convocação dos antepassados, ou o ervalista que trabalha só com ervas. Esse mundo é mais complexo do que pensamos.

Em geral, o que passa no mundo da família, no mundo íntimo, se há um problema com o marido, a mulher ou na família, desemprego ou qualquer coisa de caráter pessoal, essa relação com os antepassados é feita pelo chefe de família que é quase um sacerdote. Aqui a esfera religiosa não se autonomizou da esfera política. Portanto, no chamado poder tradicional, a mesma pessoa tem funções diversas. Eu, quando for o mais velho dos Coutos, serei o sacerdote da minha família, porque não há um deus a quem respondemos. O meu deus são os meus antepassados, os Coutos. Portanto, suponhamos que a Doris é da minha família: tem um problema, fala comigo e eu organizo essa ligação com os antepassados. Se há um problema mais vasto, imagina que há uma guerra, há fome, qualquer coisa que já diz respeito a todo o território, eu tenho de chamar o dono da terra. Aqui o dono da terra seria o "maputo", o clã maputo que deu origem ao nome da cidade. Então vamos ter de chamar o chefe tradicional, que vai trazer o seu feiticeiro, o seu curandeiro para fazer as cerimónias de ligação.

13 Qual a função dos elementos mágicos na sua literatura, por exemplo em Terra Sonâmbula? Qual a diferença em relação ao realismo mágico latino-americano?

$\mathrm{Eu}$ acho que esse nome, "realismo mágico", foi inventado por alguém quem estava de fora, que não era escritor. E acho que foi inventado fora da América Latina e fora da África, porque é importante classificar, ter uma gaveta para meter as coisas dentro. Eu acho que não é possível falar da realidade latino-americana e da africana, daquela efervescência, daquela mistura híbrida, daquela presença do mundo não visível, sem falar do mundo mágico, que no fundo não é mágico. Esse mundo é tão real como esta mesa, como esta gravadora, como estas coisas da modernidade. Sobretudo, a diferença que eu noto é o lugar dos mortos. O lugar dos mortos na América Latina é muito marcado por um grande sincretismo entre a religião católica e as religiões locais. Aqui as religiões locais são ainda completamente dominantes. A capacidade que a Igreja Católica teve de se hibridizar foi muito pequena. Aqui os mortos não morrem. Não têm o mesmo peso. Eles só têm um peso negativo quando estão zangados, quando não são chamados a participar, a governar o mundo dos vivos.

14 Como convivem hoje a ideia tradicional patriarcal da mulher como posse do homem e a ideia moderna da mulher como pessoa autónoma e autossuficiente? Como convivem a poligamia e a monogamia, o kutchinga ${ }^{6}$ e o divórcio? Como é a situação em Maputo, por exemplo?

Acho que isso acontece sem grande conflito. Portanto, não há uma espécie de uma imposição. Não há uma tentativa de definir que toda a gente tem de ser igual. Mas realmente a ideia de uma pessoa civilizada aqui tem um peso muito grande daquilo que era a apreciação dos católicos que é a dos assimilados. Uma condição primeira, para que se fosse assimilado e moderno, era ter só uma mulher. Isso já era um conflito enorme com as práticas tradicionais. Eu acho que aqui a única coisa que há a fazer é deixar que o tempo e os fenómenos da urbanização, etc., acabem por transformar esta realidade. Precisamente porque integram a mulher nos circuitos

\footnotetext{
${ }^{6}$ Ritual de purificação em que a viúva tem de ter relações sexuais com o seu cunhado mais novo antes de tornar-se esposa dele. Para mais informação, veja p. ex. MATOLA, André. Moçambique: SIDA e Hábitos Tradicionais. Maputo: Edição do Autor, 2010.
} 
da produção, da economia, do saber, do poder, etc. Eu verificava que algumas ONGs e alguns movimentos dos direitos humanos - que são muito úteis e que devem fazer o seu trabalho - têm a ideia que é por apego à consciência que se faz uma grande mudança. Não acredito nisto. É preciso que se imponham outras regras de um outro civismo no sentido de uma cultura urbana. Isso vai mudar como também está a mudar a taxa da natalidade. O número de filhos que as pessoas têm é drasticamente reduzida nas cidades. Não é tanto pelas campanhas que se fazem, mas porque as pessoas percebem que tem de ter uma outra lógica.

15 Nos anos 1960 e 1970, a FRELIMO dizia que também lutava pela igualdade da mulher. Acha que a política da FRELIMO trouxe alguma melhoria para a posição da mulher?

Acho que sim, acho que é justo dizer que sim. Podese ter muitas críticas em relação à FRELIMO, mas a FRELIMO trouxe esse componente e acho que continua a ter essa preocupação. Claro que agora já não é só a FRELIMO, somos parte do mundo. Mas é preciso ver, por exemplo, as primeiras mulheres que entraram no exército da FRELIMO, que aderiram à guerrilha era um salto de um universo para outro. Uma mulher vestir umas calças, vestir uma farda militar? Num país em que era impensável sequer a mulher ir à caça ou pescar... Uma mulher não pode pescar. Então, isso foi uma rutura drástica, dramática. A FRELIMO também introduziu outra coisa neste país que ninguém pensava: "Eu ter um chefe que fosse uma mulher?" Portanto, eu acho que a FRELIMO teve essa ousadia de propor uma sociedade em que as mulheres poderiam comandar, poderiam ter mesmo direito a ocupar os espaços que os homens tinham. Claro, mas depois há um limite, um movimento político não pode mudar a sociedade inteira.

16 O Mia aprendeu alguma língua bantu na infância?

$\mathrm{Na}$ infância, sim. A Beira tem duas línguas, o cindau e o xisena. Eu falava com fluência o xisena. Já quase me esqueci completamente, porque eu saí da Beira há 40 anos. Aqui em Maputo não encontro quase ninguém que fale xisena. Aqui aprendi uma coisa muito rudimentar de changana. Dá para eu falar na rua, um bocadinho, mas não consigo ter uma conversa.

17 Que dificuldades tem o uso do português para contar estórias que, se contadas em línguas locais, seriam provavelmente mais verossímeis, visto que as personagens falariam nas suas próprias línguas? Isto não cria um conflito?

Eu não vejo isso como um conflito, porque também quando ponho as pessoas a falar em português, não é o português que elas falariam na rua. É um português poético. A linguagem que eu quero e as personagens que eu quero não podem ser confrontados com realidade. Não quero que sejam confrontadas com a realidade. É por isso que os nomes dos lugares, das pessoas são inventados e são inventados de maneira que a pessoa perceba que ali não está um lugar concreto, ali não está uma pessoa concreta. Ali está uma proposta de um outro território. Não vejo que seja um problema para mim. Senão eu também nunca poderia falar de uma personagem feminina ou de um indiano. Há pessoas que cobram aos escritores esse sentido de realidade ou de realismo. Várias vezes me perguntaram, quando eu falo numa história de uma mulher, como é que eu posso saber, como é que eu tenho a certeza - sendo eu um homem -, então eu digo: "Eu sou uma mulher também." Eu sou sempre as personagens que eu estou a criar, porque não sou nenhuma mulher real, só aquela pessoa. É no domínio da literatura que isto tem de ocorrer. Eu não quero fazer um ensaio social, nem quero ter um texto que tenha essa tentação de substituir a realidade.

18 Quantas pessoas com que se cruza nas suas atividades diárias e profissionais como biólogo seriam capazes de ler um romance seu em português?

Muito poucas.

\section{O domínio do português nestas zonas é rudi- mentar?}

O domínio da leitura em primeiro lugar, porque mesmo que os meus livros estivessem traduzidos, as pessoas não os leriam. Para que eu falasse dos moçambicanos eu tinha sempre que traduzir em línguas locais. Imagine que a minha língua materna era o xuabo ou qualquer língua dos reis bantu. Eu podia escrever na minha língua, mas para eu ser conhecido em Moçambique, eu tinha de ser traduzido quinze ou vinte vezes para que os moçambicanos me lessem a mim. O problema que afasta as pessoas da leitura em primeiro lugar é que os moçambicanos não leem em nenhuma língua. As pessoas no campo não sabem ler. Agora, infelizmente, só aprendem a ler em português. O português passou a ter uma posição muito hegemónica no quadro das línguas.

20 Acha que no futuro pode haver pelo menos um jornal escrito numa destas línguas?

Eu espero que sim, mas não é fácil. Houve moçambicanos que tentaram publicar livros nas suas línguas maternas e foi um desastre. Venderam dez exemplares... Para que a publicação de livros, revistas ou jornais nas línguas locais seja um sucesso é preciso todo um outro movimento. É preciso que a escola 
integre este ensinamento. É preciso valorizar do ponto de vista simbólico essas línguas. É preciso criar dicionários, é preciso muita coisa que não está a acontecer, infelizmente.

\section{Como é que o Mia e a sua família viveram o tempo das guerras?}

Acho que eu tinha 10 anos quando eu comecei a ouvir falar da guerra colonial. Guerra era uma coisa que estava muito próxima. Eu não sou de Maputo, sou do Centro. Na minha casa sempre houve esta ideia de que o meu pai, apesar de ser um imigrante português, era muito simpatizante da FRELIMO. Portanto, nós não vimos a guerra como ameaça, nós vimos como uma coisa messiânica que quem nos vinha libertar estava a chegar. Então não foi uma coisa opressiva, dramática. Mas, sim, a presença dos soldados portugueses criou conflitos enormes na minha adolescência. O meu bairro transformou-se num quartel praticamente. Tenho memórias muito fortes. Escrevi muitas coisas em relação a essa espécie de território ocupado.

Depois na guerra civil vivi sempre aqui em Maputo. A ideia que eu tenho era de que às vezes eu preferia ir ao centro da guerra do que estar à margem e só ouvir falar das pessoas que morriam, dos meus amigos que foram mortos. Às vezes, ficando na margem, sofre-se mais do que estando dentro da guerra. É um sentimento de impotência, de estar cercado, de não ter saída. Nós todos os dias saíamos da manhã à procura de comida para trazer aos nossos filhos. Não tínhamos nada. Era uma sobrevivência quotidiana. E não foi uma semana, nem um mês, foram anos em que se saía à rua à procura de uma fila, íamos a correr perguntar o que é que estão a distribuir. Às vezes as pessoas nem sabiam. Parece que é leite, parece que é pão, parece que é peixe... Foi muito duro. Não posso pensar que a gente pode viver uma coisa igual.

\section{A maioria de portugueses fugiu após a indepen- dência. A sua família nunca considerou esta opção?}

Eu não sou colono português. A minha família toda nasceu aqui. Os meus pais foram os fundadores de uma espécie de um clã. Mas os meus pais nasceram em Portugal, e vieram para cá muito jovens. Eles voltaram uma vez, ficaram um mês, mas não conseguiram ficar lá. Eles perderam o lugar no mundo. Já não tinham lugar lá, não tinham lugar aqui. Acho que eles ficaram numa espécie de limbo. Mas nós, eu, os meus irmãos, o resto da minha família (os meus primos, sobrinhos e agora filhos e netos), todos nascemos aqui. Não conhecemos outro lugar no mundo. Portanto, não se punha a questão do regresso para nós. Nunca nos ocorreu sair.
23 Faço esta pergunta porque me interesso também pela literatura dos "retornados", aqueles colonos e filhos de colonos que regressaram a Portugal.

Essa gente às vezes diz-se moçambicano ou angolano, porque tem uma relação de afeto com aquele país, mas eu acho que a situação é diferente.

24 Há muito silêncio na população em relação à guerra colonial e à guerra civil, provavelmente porque os traumas ainda não são superados. Pensemos em Jesusalém. Quais são os riscos deste esquecimento propositado?

Eu acho que aqui há uma mistura. É preciso esquecer, mas por outro lado também há uma apreciação de que as raízes do conflito estão presentes ainda, como nós estamos a ver agora. Acho que há uma espécie de sabedoria. É melhor não mexer ali porque os demónios ainda estão naquela casa. Seria diferente se tivéssemos superado completamente aquelas tensões. Que o país se pacificou foi quase um milagre para dizer a verdade. Foi possível sobretudo por causa desta família rural que em Moçambique continua a ser o elemento fundamental. Do ponto de vista social, a família reintegrou toda esta sociedade que estava estilhaçada, que estava partida. Mas essa paz foi feita num certo nível. É uma espécie de uma capa. Por baixo, todos sentimos que há qualquer coisa que não está completamente resolvida.

\section{O Outro Pé da Sereia contém uma parte his-} tórica que se desenrola no século XVI. Por que é preciso recordar hoje em dia esta época distante da escravatura?

Precisamos porque é um passado que não passou. Esta mesma estratégia do silêncio que se criou em relação à guerra civil foi sendo criada em relação às outras guerras e outros fenómenos traumáticos. Se a Doris procurar em Moçambique inteiro e falar sobre a escravatura é outro esquecimento, parece que nunca houve. Acho que a literatura pode ter a função de mostrar que isso está ainda vivo e é preciso sabermos lidar com isso. A literatura não pode resolver, mas pode fazer um convite para mostrar que, de uma maneira tranquila, é necessário assimilarmos isso como parte da nossa própria história, do nosso tempo.

26 Há hoje em dia movimentos culturais de recuperação da memória histórica, por exemplo a memória silenciada das antigas crianças soldados?

Eu não conheço. Mas há um fenómeno. Na mesma família havia alguém que tinha sido soldado da FRELIMO e outro que tinha sido soldado de RENAMO e depois se reconciliaram. Precisamente para as crianças que 
cometeram crimes, há uma espécie de cerimónia, de um ritual. Quem pode falar muito disso é um psicólogo moçambicano, Boia Efraime Junior, ${ }^{7}$ que fez um estudo muito bem feito sobre como é que esses rituais obrigavam ao esquecimento. Isso, do ponto de vista local, das próprias pessoas que viveram a situação e dos movimentos cívicos e ONGs. Acho que todos nós partilhamos essa ideia que é melhor não mexer, porque pode ser uma caixa de Pandora.

Recebido: 18 de agosto 2014 Aprovado: 31 de outubro 2014 Contato: doris.wieser@phil.uni-goettingen.de

\footnotetext{
7 Veja por exemplo o seguinte ensaio: EFRAIME JÚNIOR, Bóia. Trauma e migração: os traumas psíquicos das crianças soldado. Diversitas, v. 1 , n. 1, 2013. Disponível em: <http://www.revistas.usp.br/diversitas/article/ view/58378>. Acesso em: 07 out. 2014.
} 